\title{
Implementation of Mathematical Models of Buck Converter using MatLab/Simulink
}

\author{
S. Krishnaveni \\ Department of Electrical and Electronics Engineering, Sri Sivasubramaniya Nadar College of Engineering, \\ Kalavakkam, Tamilnadu, India
}

\begin{abstract}
I. INTRODUCTION
Mathematical equations which have been used to describe the behaviour and performance of any particular converters are the foundation of models. The power electronic converters are developed either as a system model or a circuit model. The switching function concept can be introduced along with the system model to reach out the expected outputs [1-3]. Hence the mathematical models are used to predict the performance and these predictions might help the design Engineers to think various control strategies $[4]$.
\end{abstract}

Mathematical modelling of a circuit has complete control over the simulation process which takes a smaller execution time but circuit model consumes less initial setup time. The transfer function model is a simple one, and also applicable to both time domain and frequency domain analysis. But, it is only suitable for single input and single output model. But, the state space model overcomes this difficulty [5-7].

The simple buck converter is considered in this paper to detail about the mathematical models. Buck converter is a second order converter which consists of a diode, one inductor, a semiconductor switch, one capacitor, one load resistor and a DC input voltage source. It converts high voltage into low voltage and finds applications that require fast line and load transient responses as in voltage regulators [5].

\section{METHODS AND MATERIAL}

The buck converter topology is shown in Fig. 1 where the switch can be any one of MOSFET, BJT, IGBT or 
GTO. The switch is triggered by an external pulse width modulation scheme whose pulse period is $\mathrm{T}$ and duty cycle is $\mathrm{D}$.

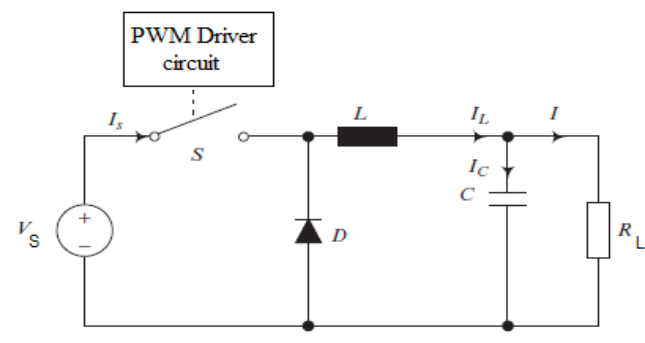

Figure 1: Buck converter

The equivalent circuits when the switch is $\mathrm{ON}$ from 0 to DT and OFF from DT to T are shown in Fig. 2.

Based on the assumption of continuous conduction mode (CCM) of operation, the average inductor current over one complete cycle of period $\mathrm{T}$ is zero and the equations can be derived.

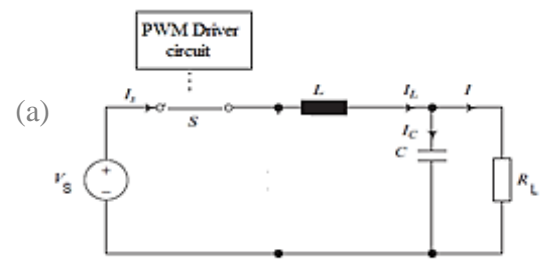

(b)

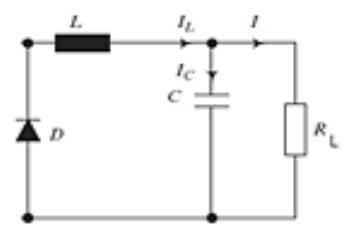

Figure 2: When the switch is (a) ON (b) OFF

$$
\begin{gathered}
\frac{\left(\mathrm{V}_{\mathrm{s}}-\mathrm{V}_{\mathrm{o}}\right) \mathrm{DT}}{\mathrm{L}}+\frac{\left(-\mathrm{V}_{\mathrm{o}}\right)(1-\mathrm{D}) \mathrm{T}}{\mathrm{L}}=0 \\
\frac{\mathrm{V}_{\mathrm{o}}}{\mathrm{V}_{\mathrm{s}}}=\mathrm{D}
\end{gathered}
$$

The buck converter waveform in CCM is shown in Fig. 3. During the switch ON period, the inductor current increases to ILmax and drops to ILmin linearly during switch OFF period. From Fig 3.a, the average inductor current ILavg is derived as in equation (3)-(4).

$$
\mathrm{I}_{\text {Lavg }}=\frac{\text { Area } 1+\text { Area } 2+\text { Area } 3}{\mathrm{~T}}
$$

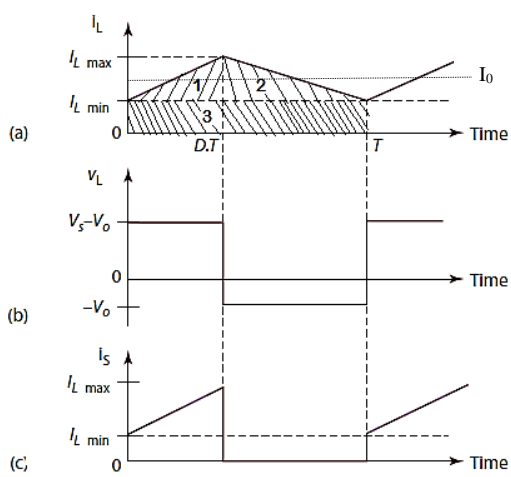

Figure 3: Buck converter waveforms

$$
=\frac{\left(\frac{1}{2} \times \mathrm{DT} \times\left(\mathrm{I}_{\mathrm{Lmax}}-\mathrm{I}_{\mathrm{L} \text { min }}\right)+\frac{1}{2} \times(1-\mathrm{D}) \mathrm{T} \times\left(\mathrm{I}_{\mathrm{L} \max }-\mathrm{I}_{\mathrm{L} \min }\right)+\mathrm{I}_{\mathrm{Lmin}} \times \mathrm{T}\right)}{\mathrm{T}}
$$

The average load current is given by Equation (5).

$$
\mathrm{I}_{0}=\frac{\mathrm{V}_{0}}{\mathrm{R}_{\mathrm{L}}}
$$

From Fig. 3a,

$$
\begin{gathered}
\mathrm{I}_{\mathrm{L} \max }=\mathrm{I}_{0}+\frac{\Delta \mathrm{i}_{\mathrm{L}}}{2} \text { and } \mathrm{I}_{\mathrm{L} \min }=\mathrm{I}_{0}-\frac{\Delta \mathrm{i}_{\mathrm{L}}}{2} \\
\text { where } \Delta \mathrm{i}_{\mathrm{L}}=\frac{\left(\mathrm{V}_{\mathrm{S}}-\mathrm{V}_{0}\right) \times \mathrm{DT}}{\mathrm{L}}
\end{gathered}
$$

Using equation (2),

$$
\begin{aligned}
& I_{L \max }=D V s \times\left[\frac{1}{R_{L}}+\frac{(1-D) T}{L}\right] \\
& I_{L \min }=D V s \times\left[\frac{1}{R_{L}}-\frac{(1-D) T}{L}\right]
\end{aligned}
$$

The critical inductance to retain CCM is obtained by equating ILmin to zero.

$$
\text { Lcrit }=\frac{(1-\mathrm{D}) \mathrm{T} \times \mathrm{R}_{\mathrm{L}}}{\mathrm{L}}
$$

\section{III.MATHEMATICAL MODELS AND SIMULATION}

The mathematical models are carried out for the following design parameters. The input voltage, $\mathrm{V}_{\mathrm{s}}=$ $48 \mathrm{~V}$, the output voltage, $\mathrm{V}_{\mathrm{o}}=12 \mathrm{~V}$, the nominal output power, $\mathrm{P}_{\mathrm{o}}=200 \mathrm{~W}$, the switching frequency, $\mathrm{f}_{\mathrm{s}}$ $=50 \mathrm{kHz}$, the maximum current ripple in the output inductor $\Delta \mathrm{I}_{\mathrm{Lo}}=$

$10 \% \mathrm{I}_{\mathrm{o}}$, and the maximum output voltage ripple $\Delta \mathrm{V}_{\mathrm{o}}=$ $0.5 \% \mathrm{~V}_{\mathrm{o}}$. 
For an output voltage of $48 \mathrm{~V}$, the corresponding duty cycle $\mathrm{D}=\mathrm{V}_{\mathrm{o}} / \mathrm{V}_{\mathrm{s}}=12 / 48=0.25$ and the output current $I_{o}=200 / 12=16.6$ A. Based on the specifications, the required output inductance $\mathrm{L}$ and output capacitance $\mathrm{C}$ can be obtained as follows.

$$
\begin{aligned}
& \mathrm{L} \geq \frac{(1-\mathrm{D}) \mathrm{T} \times \mathrm{R}_{\mathrm{L}}}{\mathrm{L}}=109 \mu \mathrm{H} \\
& \mathrm{C} \geq \frac{\Delta \mathrm{I}_{\mathrm{L}} \times \mathrm{T}}{8 \times \Delta \mathrm{V}_{0}}=69 \mu \mathrm{F}
\end{aligned}
$$

\section{A. Circuit Model}

It is a graphical method of representing the circuit by using the physical components available in the Simulink library. It is a simple and a straight forward method. Fig. 4 shows the circuit model of Buck converter for the chosen design parameters and the output voltage is shown in Fig. 5.

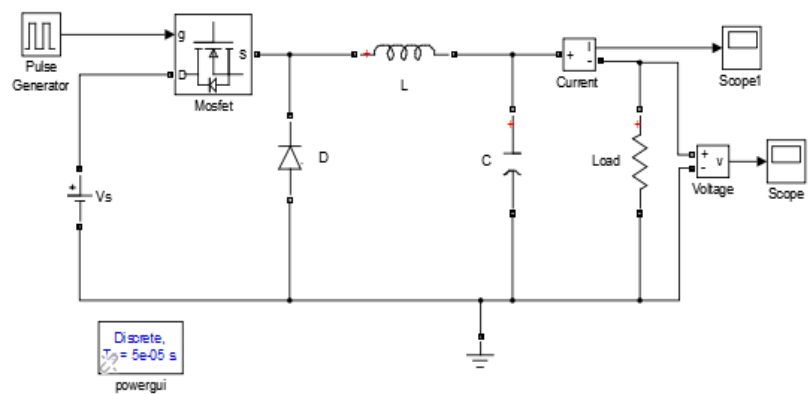

Figure 4: Circuit model of Buck converter

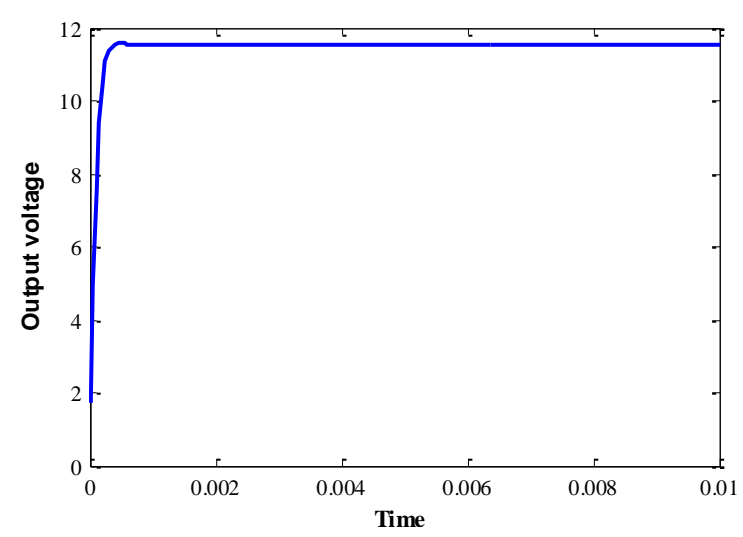

Figure 5: Output voltage of circuit model

\section{B. Mathematical Model}

According to the Kirchhoff's current and Kirchhoff's voltage laws, the basic differential equations can be derived by referring the circuit shown in Fig. 2 for the ON and OFF states.

$$
\begin{aligned}
& I_{c}(t)=I_{L}(t)-I_{0}(t) \\
& V c(t)=\frac{1}{C} \int I_{c}(t) d t=\frac{1}{C} \int\left(I_{L}(t)-I_{0}(t)\right) d t \\
& I_{0}(t)=\frac{V_{0}(t)}{R_{L}} \\
& V_{L}(t)=V_{s}(t)-V_{0}(t) \times D T-\left(V_{0}(t)\right) \times(1-D) T \times \operatorname{sign}\left(I_{L}\right)
\end{aligned}
$$

The inductor current may take either positive or negative value based on the circuit elements. The equations (11) - (13) are used to implement the mathematical model in Simulink and as shown in Fig. 6 and the output voltage is shown in Fig.7.

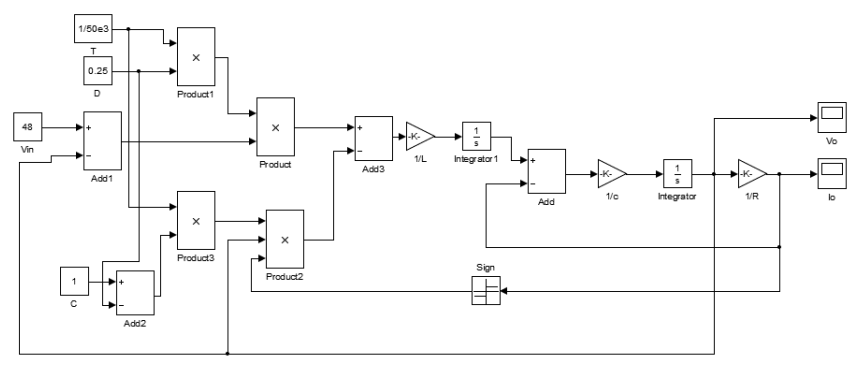

Figure 6: Mathematical model of buck converter

When the switch is ON for the period of DT,

$$
\begin{aligned}
& \frac{d I_{L}(t)}{d t}=\frac{V_{s}-V_{0}}{L} \\
& \frac{d V_{C}(t)}{d t}=\frac{I_{L}-I_{0}}{C} \\
& V_{0}(t)=V_{c}(t)
\end{aligned}
$$

When the switch is OFF for the period of (1-D)T,

$$
\begin{aligned}
& \frac{d I_{L}(t)}{d t}=\frac{-V_{0}}{L} \\
& \frac{d V_{C}(t)}{d t}=\frac{I_{L}-I_{0}}{C} \\
& V_{0}(t)=V_{c}(t)
\end{aligned}
$$

The output parameters over one complete period $\mathrm{T}$ can be calculated by 


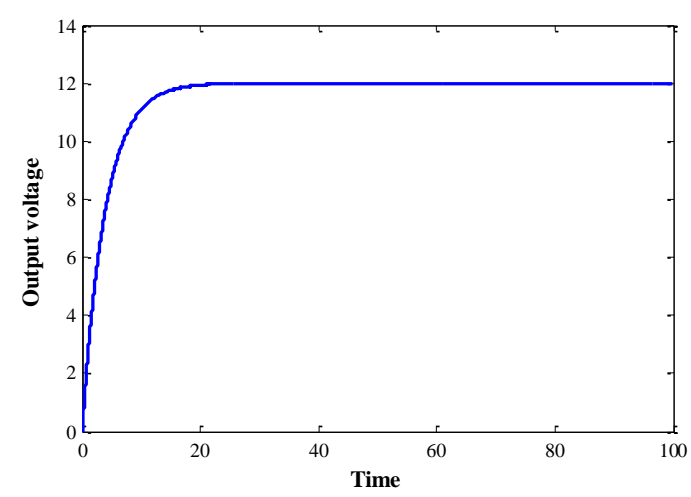

Figure 7: Output voltage
From the Fig 1, the differential equations can be written for the inner mesh and outer mesh as follows.

$$
\begin{aligned}
& V_{S}(t)=L \frac{d I_{L}(t)}{d t}+\frac{1}{C} \int I_{C}(t) d t \\
& V_{S}(t)=L \frac{d I_{L}(t)}{d t}+I_{0}(t) R \\
& V_{S}(t)=L \frac{d I_{L}(t)}{d t}+\left(I_{L}(t)-I_{C}(t)\right) R
\end{aligned}
$$

Laplace transform is applied to equation (14) to derive the transfer functions of $\mathrm{I}_{\mathrm{L}}(\mathrm{s})$ and $\mathrm{V}_{\mathrm{O}}(\mathrm{s})$.

$$
\begin{aligned}
\mathrm{V}_{\mathrm{s}}(\mathrm{s}) & =\mathrm{LSI}_{\mathrm{L}}(\mathrm{s})+\left(\mathrm{I}_{\mathrm{L}}(\mathrm{s})-\mathrm{I}_{\mathrm{C}}(\mathrm{s})\right) \mathrm{R} \\
\mathrm{I}_{\mathrm{C}}(\mathrm{s}) & =\frac{(\mathrm{LS}+\mathrm{R}) \mathrm{I}_{\mathrm{L}}(\mathrm{s})-\mathrm{V}_{\mathrm{s}}(\mathrm{s})}{\mathrm{R}} \\
\mathrm{V}_{\mathrm{S}}(\mathrm{s}) & =\mathrm{LSI}_{\mathrm{L}}(\mathrm{s})+\frac{1}{\mathrm{CS}}\left[\frac{(\mathrm{LS}+\mathrm{R}) \mathrm{I}_{\mathrm{L}}(\mathrm{s})-\mathrm{V}_{\mathrm{s}}(\mathrm{s})}{\mathrm{R}}\right] \\
\frac{\mathrm{V}_{\mathrm{S}}(\mathrm{s})}{\mathrm{I}_{\mathrm{L}}(\mathrm{s})} & =\frac{\mathrm{RLCS}^{2}+\mathrm{LS}+\mathrm{R}}{1+\mathrm{RCS}} \\
\frac{\mathrm{V}_{0}(\mathrm{~s})}{\mathrm{V}_{\mathrm{s}}(\mathrm{s})} & =\frac{\mathrm{R}}{\mathrm{RLCS}^{2}+\mathrm{LS}+\mathrm{R}}
\end{aligned}
$$

Equation (15) is implemented in Simulink and shown in Fig. 8 and its output voltage is shown in Fig. 9.

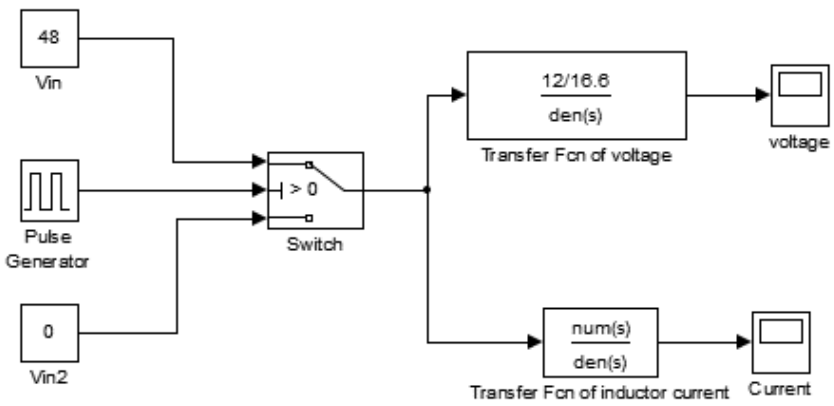

Figure 8: Transfer function model of buck converter

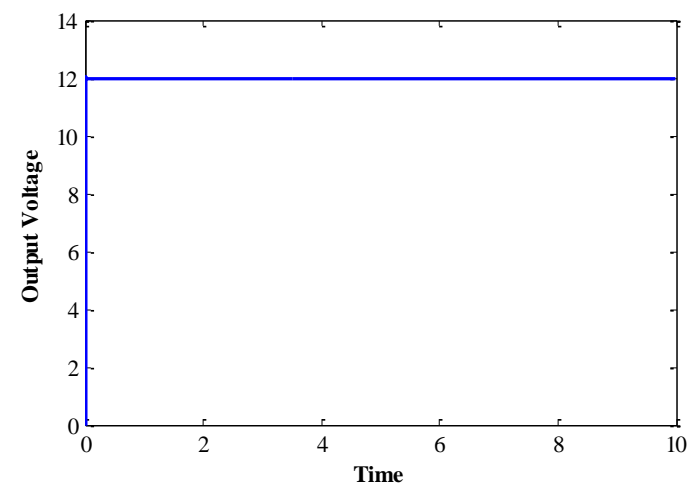

Figure 9: Output voltage

\section{B. State space average Model}

The state equations are written for the buck converter as follows.

$$
\begin{aligned}
& \dot{\mathrm{X}}=\mathrm{AX}+\mathrm{BU} \\
& \mathrm{Y}=\mathrm{CX}+\mathrm{DU}
\end{aligned}
$$

Here, $\mathrm{X}$ is the state variable and $\mathrm{Y}$ is the output. $\mathrm{A}, \mathrm{B}$, $\mathrm{C}$ and $\mathrm{D}$ are state Matrices. From equation (11) and $(12)$

$$
\begin{aligned}
& \dot{\mathrm{X}}=\left[\begin{array}{c}
\frac{\mathrm{dI}_{\mathrm{L}}(\mathrm{t})}{\mathrm{dt}} \\
\frac{\mathrm{dV}_{\mathrm{C}}(\mathrm{t})}{\mathrm{dt}}
\end{array}\right]=\left[\begin{array}{cc}
0 & -\frac{1}{\mathrm{~L}} \\
\frac{1}{\mathrm{C}} & -\frac{1}{\mathrm{CR}}
\end{array}\right]\left[\begin{array}{c}
\mathrm{I}_{\mathrm{L}}(\mathrm{t}) \\
\mathrm{V}_{\mathrm{C}}(\mathrm{t})
\end{array}\right]+\left[\begin{array}{c}
\frac{1}{\mathrm{~L}} \\
0
\end{array}\right] \mathrm{V}_{\mathrm{S}} \\
& \mathrm{Y}=\left[\begin{array}{ll}
0 & 1
\end{array}\right]\left[\begin{array}{c}
\mathrm{I}_{\mathrm{L}}(\mathrm{t}) \\
\mathrm{V}_{\mathrm{C}}(\mathrm{t})
\end{array}\right]+0
\end{aligned}
$$

Equation (17) is implemented in Simulink for both the switch ON and OFF conditions and shown in Fig.10. The output voltage is shown in Fig. 11.

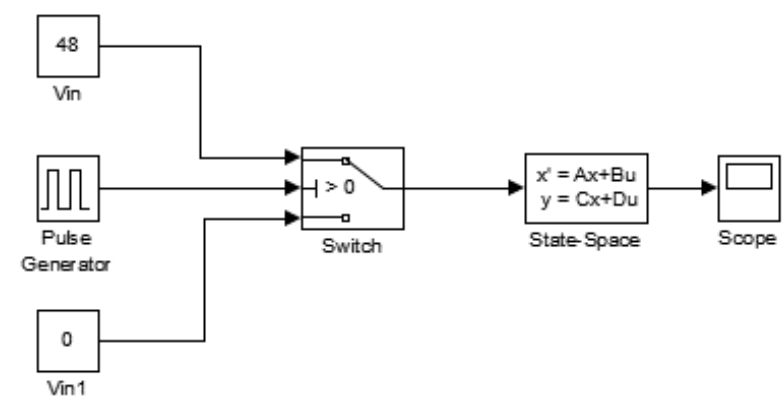

Figure 10: State space model of buck converter 


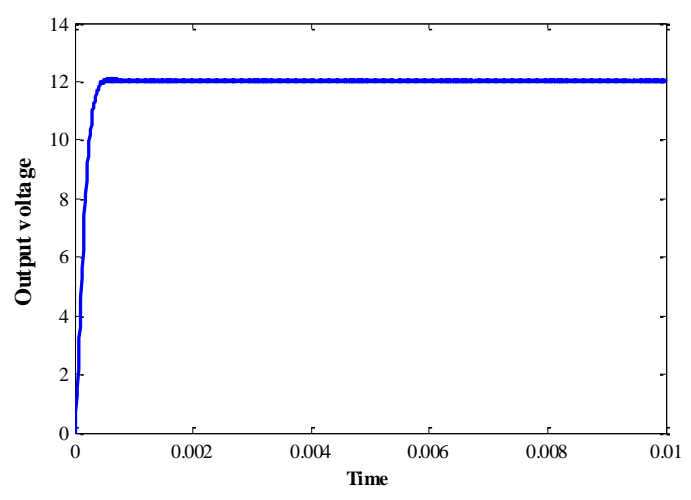

Figure 11: Output voltage

\section{IV.CONCLUSION}

The mathematical equations are derived and modified based on the models selected. The simulation is implemented in Simulink and the output voltages for each model are presented in this paper. The physical model looks very simple to construct but the result is not matched with the designed value but the other three models produce the designed output voltage. The transfer function model produces the output voltage with zero rise time than three models. The rise time to reach the steady state value is larger in case of mathematical model and this may be due to the delays created by each block used in the circuit. Hence, the mathematical models are more suitable in the design of controller.

\section{REFERENCES}

[1]. B.K. Lee and M. Ehsani: "A simplified functional simulation model for three-phase voltage source inverter using switching function concept", IEEE Transactions on Industrial Electronics; Vol.48, No.2, April 2001; pp. 309-321.

[2]. V.F. Pires and J.F.A. Silva: "Teaching nonlinear modelling, simulation and control of electronic power converters using MATLAB/SIMULINK", IEEE Transactions on Education; Vol.45, No.3, August 2002; pp. 253-256.
[3]. B. Baha: "Modelling of resonant switched-mode converters using SIMULINK", IEE Proceedings, Electric Power Applications; Vol.145, No.3, May 1998; pp. 159-163

[4]. C.-M. Ong: Dynamic Simulation of Electric Machinery Using MATLAB/SIMULINK, Upper Saddle River, NJ: Prentice Hall; 1998.

[5]. Mohammad Reza, "An Improved State Space Average Model of Buck DC-DC Converter with all of the System Uncertainties", in International Journal on Electrical Engineering and Informatics, Volume 5, No 1, March 2013.

[6]. C.A. Canesin, F.A.S. Goncalves, L.P Sampaio, "Simulation Tools of DC DC Converters for Power Electronics Education", 13th European Conference on Power Electronics and Applications (EPE), 2009, pp. 1-10.

[7]. Viswanatha V, Venkata Siva Reddy R “ A Complete Mathematical Modeling, Simulation and computational Implementation of Boost Converter Via MATLAB/Simulink, International Journal of Pure and Applied Mathematics, Volume 114 No. 10 2017, 407-419

\section{Cite this article as :}

S. Krishnaveni , "Implementation of Mathematical Models of Buck Converter using MatLab/Simulink ", International Journal of Scientific Research in Science and Technology (IJSRST), Online ISSN : 2395-602X, Print ISSN : 2395-6011, Volume 8 Issue 3, pp. 516-520, May-June 2021. Available at doi : https://doi.org/10.32628/IJSRST2183106 Journal URL : https://ijsrst.com/IJSRST2183106 